Hammersmith Staff Rounds

\title{
Gas gangrene
}

\author{
Overwhelming infection responsive to surgical and medical treatment
}

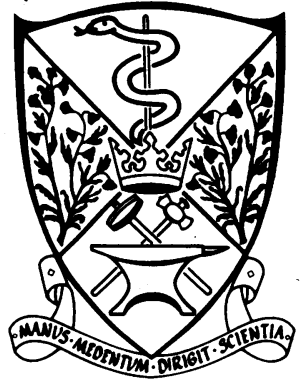

Department of Medicine, Hammersmith Hospital, London W12 OHS

Case presented by:

P J Lehner, MRCP, medical registrar

H Powell, FFARCS,

anaesthetics senior registrar

Chairman:

C T Dollery, FRCP, professor of medicine

Discussion group:

J Cohen, FRCP, reader in infectious diseases

S R Bloom, FRCP, professor of endocrinology

H J F Hodgson, FRCP, reader in gastroenterology

A J Rees, FRCP, professor of nephrology

J Lumley, FFARCs, senior lecturer, anaesthetics

C D Pusey, FRCP, senior

lecturer, renal medicine

E R T C Owen, FRCS, senior

registrar, surgery

Series edited by:

Dr Robert Winter.

BMF 1991;303:240-2
Gas gangrene, an overwhelming infection caused by Clostridium perfringens, constitutes both a medical and a surgical emergency. The organism is not an opportunistic pathogen, but infection occurs when local tissue conditions and heavy bacterial contamination lead to tissue hypoxia, predisposing to anaerobic infection. We describe gas gangrene occurring in an intravenous drug misuser and discuss the role of early surgery and management of septicaemic shock.

\section{Case history}

A 35 year old intravenous drug misuser presented with a 24 hour history of sweating, fevers, and increasing confusion. On examination he was unwell with a temperature of $38.3^{\circ} \mathrm{C}$, a tachycardia of 120 beats/min, cool peripheries, and a blood pressure of $90 / 50 \mathrm{~mm} \mathrm{Hg}$. There were no signs of infective endocarditis and no focus of infection was evident.

Investigations showed normocytic normochromic anaemia (haemoglobin concentration $92 \mathrm{~g} / \mathrm{l}$ ), white blood cell count of $12.5 \times 10^{9} / 1$, and platelet count of $312 \times 10^{9} / 1$; a blood film showed toxic neutrophilia but no evidence of disseminated intravascular coagulation. The prothrombin time was raised at 18 seconds (normal 12-15 seconds), and his activated partial thromboplastin time was 40 seconds (normal 30-46 seconds). He had renal impairment with raised urea $(14.7 \mathrm{mmol} / \mathrm{l})$ and creatinine concentrations $(273 \mu \mathrm{mol} / \mathrm{l})$.

Initial management consisted of resuscitation with intravenous fluids and treatment with imipenem (500 mg, six hourly). Over the next five hours he became delirious and his temperature rose to $40^{\circ} \mathrm{C}$. His right leg, which had been normal on admission, became tense and oedematous with a bluish skin discoloration spreading from the thigh up to the groin and anterior abdominal wall. There was no evidence of crepitus, but soft tissue radiography of the leg showed gas outlining the muscle bundles (fig 1). Clostridial myonecrosis was diagnosed and intravenous benzylpenicillin started $(2 \cdot 4 \mathrm{~g}$, two hourly).

Exploration of the subcutaneous tissue after full

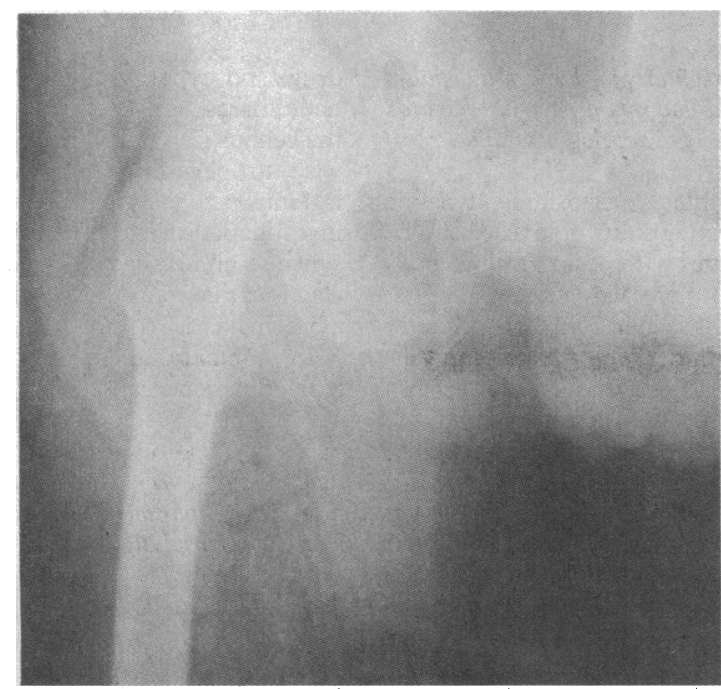

length incision on the medial aspect of the leg showed no evidence of infection. On incision of the deep fascia, however, pungent gas was suddenly released. Extensive necrotic muscle in the adductor compartment was found, and his adductor magnus, adductor longus, adductor brevis, and gracilis muscles had to be removed. Bleeding was controlled by ligature. The wound was loosely packed and left open, and by the end of the operation there was no significant bleeding. Figure 2 shows the fasciotomy. Gram stain of pus and necrotic tissue showed Gram positive rods, which were later confirmed as $C$ perfringens, and this organism was also grown from all three sets of blood cultures.

On return to the intensive care unit the patient bled extensively from his wound. He required 22 units of blood over eight hours and also received fresh frozen plasma (8 units), platelets (12 units), cryoprecipitate, vitamin $\mathrm{K}(10 \mathrm{mg})$, and calcium gluconate ( $20 \mathrm{mg})$, but he remained hypotensive with continued bleeding. $\mathrm{He}$ required further inotropic support with dobutamine (12 $\mu \mathrm{g} / \mathrm{kg} / \mathrm{min})$, dopamine ( $3 \mu \mathrm{g} / \mathrm{kg} / \mathrm{min})$, and noradrenaline $(0 \cdot 11 \mu \mathrm{g} / \mathrm{kg} / \mathrm{min})$. There was evidence of severe rhabdomyolysis (creatine kinase activity $14400 \mathrm{IU} / 1$ and myoglobulinuria), but his renal function did not deteriorate further.

After 24 hours further massive bleeding occurred, and he was taken to theatre for identification of bleeding points. This required control of the external iliac artery and exploration of the groin, where extensive indurated tissue was found, together with large dilated vessels due to probable arteriovenous fistulas. The bleeding was eventually controlled by ligating the profunda femoris and its branches, but by this stage he had received 86 units of blood.

He remained septicaemic, inotrope dependent, and ventilated for the next five days. Haemodynamic monitoring with a pulmonary artery flow catheter was used to guide fluid replacement and optimise cardiac output, oxygen consumption, and delivery of oxygen to tissue (fig 3). Other complications in the intensive care unit included the adult respiratory distress syndrome and areas of necrotic skin that required further surgery and skin grafting. Treatment was continued with imipenem (500 mg, six hourly) and benzylpenicillin $(2.4 \mathrm{~g}$, four hourly) for three weeks.

Over the next 10 days he gradually improved, was extubated, and weaned off the inotropes, and his renal function returned to normal. It remained too early to assess what remaining function there would be in his injured leg.

\section{Comment}

Gas gangrene is a rare condition, usually occurring âfter trauma. If civilian trauma infection normally results from road traffic accidents, crush injuries, or gunshot wounds. The prognosis for gas gangrene complicating battlefield trauma has steadily improved because of good local field hospitals, the use of penicillin, and early radical surgery. During the first world war $5 \%$ of battlefield trauma was complicated by gas gangrene, while in the Vietnam war infection was seen in $0.002 \%$ of casualties and there were no reported cases in the Falklands conflict. ${ }^{23}$ When
FIG 1-Soft tissue radiograph showing gas outlining muscle bundles of jight leg in patient with gas gangrene 
surgical debridement is not possible hyperbaric oxygen may halt the spread of the infection and demarcate necrotic tissue. In addition, pain and systemic toxicity are reduced. ${ }^{4}$

The source of infection in our patient was not established. $C$ perfringens is ubiquitous, being found in the soil and as part of normal gut flora, and has also been reported to contaminate "street" heroin. ${ }^{5}$ Gas gangrene occasionally complicates deep intramuscular injection in diabetic patients, ${ }^{6}$ but despite the high incidence of soft tissue infections in intravenous drug misusers, in particular necrotising fasciitis, ${ }^{7}$ clostridial myonecrosis is not a recognised complication of infection in this group. Our patient had been injecting substances into his groin, and surgical exploration found the tissues to be traumatised, although he denied recent injection into this area. The source of infection may therefore have been endogenous. He refused to give informed consent to testing for antibodies to HIV; however, $C$ perfringens infection is not more common in patients infected with HIV.

The cause of septicaemic shock in patients infected with $C$ perfringens is only partially understood. Gram positive organisms such as Staphylococcus aureus and $C$ perfringens do not contain endotoxin, which is associated with shock in Gram negative septicaemia, although Gram. positive organisms have produced cardiovascular abnormalities with haemodynamic profiles similar to those in Gram negative shock. ${ }^{8}$ This was thought to be due to leakage of endotoxin across the gut wall, but endotoxin has not been detected in serum from these patients. ${ }^{8} C$ perfringens produces at least 20 exotoxins. ${ }^{9}$ Exotoxin from certain strains of $S$ aureus is responsible for the toxic shock syndrome, and Streptococcus pyogenes has been associated with a streptococcal toxic shock syndrome..$^{10}$ Many of the clinical features of gas gangrene, including the local tissue destruction and the profound systemic effects, are thought to be caused by specific exotoxins. Studies on two highly purified clostridial exotoxins, $\alpha$ and $\theta$, have shown that both produce profound hypotension when injected intravenously. ${ }^{11}$ The $\alpha$ toxin produces a dose dependent reduction in myocardial function in isolated rabbit atrial preparations while the $\theta$ toxin is able to produce shock only indirectly. Shock in $C$ perfringens infection is probably mediated by both a direct myocardial depressant factor and a toxin induced release of endogenous mediators, which produce the cardiovascular abnormalities. One of these mediators, tumour necrosis factor, has been shown to reproduce the complex haemodynamic changes of FIG 2-Full length fasciotomy of leg with gangrene immediately Gram negative septic shock in animals. ${ }^{12}$

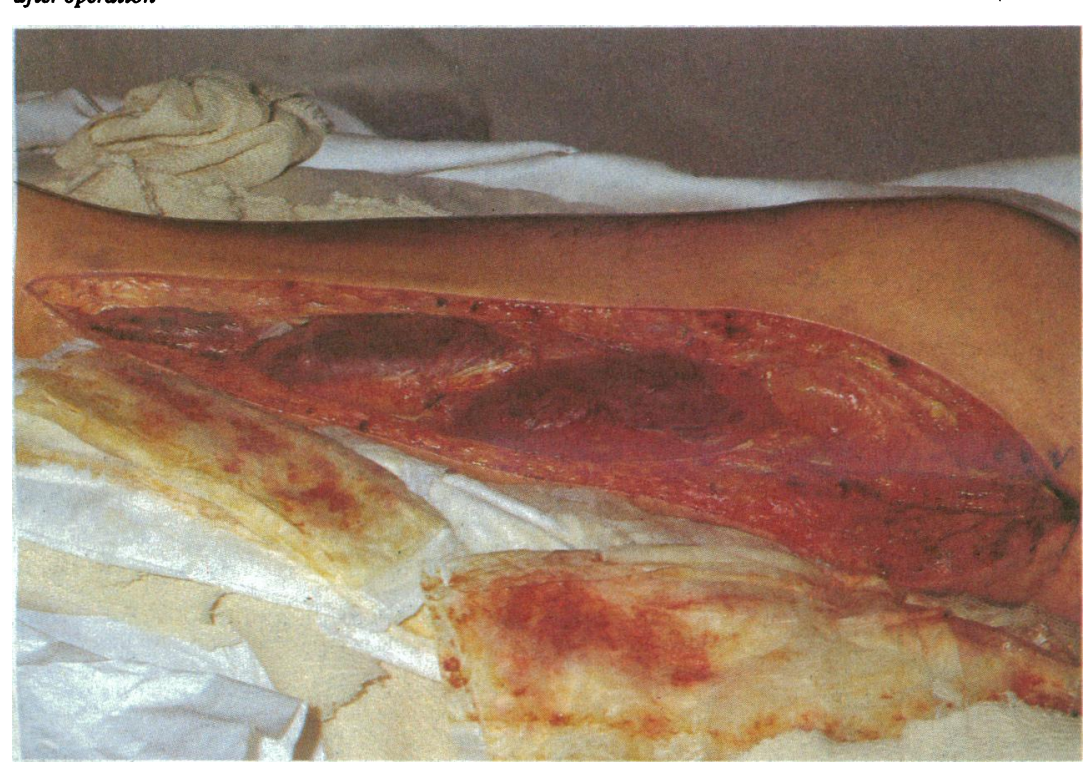

Septicaemic shock is one of the commonest causes of admissions to the intensive care unit and has a mortality of $20-70 \% .{ }^{13}$ High mortality results from severe falls in systemic vascular resistance, myocardial depression, or multiple organ failure. Studies suggest that as oxygen uptake by tissues is often inadequate in patients with septicaemia, treatment should be aimed at optimising oxygen delivery to the tissues. Thus adequate arterial oxygen saturation and haemoglobin concentration are essential. The cardiac index is also critical for oxygen uptake. The index should be optimised by using colloidal fluid to raise the pulmonary artery wedge pressure to $18 \mathrm{~mm} \mathrm{Hg}$. Colloidal solutions are preferred to crystalloid solutions as they remain within the intravascular compartment rather than spread throughout the extracellular fluid. Once optimal intravascular volume has been attained dobutamine should be started for inotropic support of the heart. The dose of dobutamine is progressively increased until there is no further improvement in oxygen uptake. Since dobutamine also stimulates peripheral $\beta$ adrenoceptors it may produce vasodilatation and a fall in mean arterial pressure, which can be treated with further colloid volume infusion.

In some patients this regimen of vigorous fluid administration and inotropic support of the heart fails to produce an adequate mean arterial pressure $(>70 \mathrm{~mm} \mathrm{Hg}$ ) and dopamine or noradrenaline are required, as in our case. These vasopressor drugs maintain coronary and cerebral blood flow but at the expense of peripheral vascular constriction and compromised peripheral tissue perfusion. Only the minimal dose required to produce a satisfactory mean arterial pressure should be given.

Figure 3 includes the management targets in patients with shock suggested by Shoemaker et al.' Based on this regimen they reported a reduction in postoperative mortality of critically sick patients from $33 \%$ to $4 \% .{ }^{14}$ Even higher cardiac parameters may be required to optimise tissue oxygen delivery in patients with septic shock. ${ }^{15}$

\section{Discussion}

JC: This case illustrates how our approach to the management of shock has evolved in recent years. Unusually, the patient experienced both haemorrhagic and septic shock, necessitating separate and specific modifications to his haemodynamic support. In terms of pathogenesis, it underlines the fact that bacterial and host factors contribute to this clinical state. The possibility that part of the hypotension is due to myocardial depressant factors has recently received renewed attention. One explanation is that tumour necrosis factor, one of the major mediators of shock, reduces the ability of cardiac myocytes to respond to $\beta$ adrenergic stimuli. ${ }^{16}$

It is unlikely that the patient injected the organism directly, and we must therefore assume that his infection was endogenous. Non-traumatic gas gangrene is well described, especially in the setting of bowel disease, and we will need to take a closer look at his bowel as his condition improves. The patient was bacteraemic. This is uncommon in clostridial myonecrosis, occurring in only $10-15 \%$ of cases, and is rare in traumatic cases, making endogenous infection even more likely.

CTD: What factors in his muscle preceded infection with clostridium? Was there an episode of rhabdomyolysis or some other event, leading to necrotic tissue, that may have preceded the bacteraemia?

JC: He had no immediate history of preceding trauma or injury to the leg. Metastatic infection can occur at any site, even in normal tissue. However, 

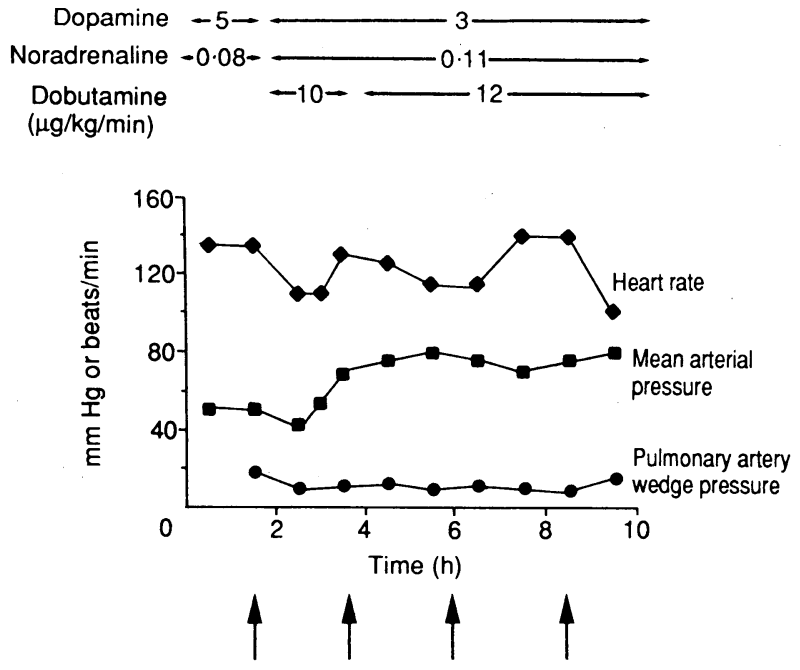

$\mathrm{PaO}_{2}(\mathrm{kPa})$

Haemoglobin $(\mathrm{g} / \mathrm{l})$

Cardiac output (l/min)

Cardiac index $\left(1 / \mathrm{min} / \mathrm{m}^{2}\right)$

Systemic vascular resistance

(dyne.s/cm ${ }^{5}$ )

Oxygen delivery $\left(\mathrm{ml} / \mathrm{min} / \mathrm{m}^{2}\right)$

Oxygen consumption

$\left(\mathrm{ml} / \mathrm{min} / \mathrm{m}^{2}\right)$

$(\mu \mathrm{g} / \mathrm{kg} / \mathrm{min})$

Target $^{-1}$
Noradrenaline $-0.08--0.11-12-10--12$

\begin{tabular}{rrrrr}
$(>10)$ & 33 & 22 & 20 & 18 \\
$(100-120)$ & 93 & 87 & 117 & 103 \\
$(>8 \cdot 4)$ & $5 \cdot 2$ & $8 \cdot 1$ & $8 \cdot 5$ & $13 \cdot 0$ \\
$(>4 \cdot 5)$ & $2 \cdot 8$ & $4 \cdot 4$ & $4 \cdot 6$ & $7 \cdot 0$ \\
& & & & \\
$(\sim 1000)$ & 560 & 660 & 650 & 400 \\
$(>600)$ & 362 & 526 & 743 & 1001 \\
$(>170)$ & 90 & 132 & 186 & 200 \\
& \multicolumn{5}{|l|}{} \\
\hline 480 & 2220 & 1000 & 400 & \\
\hline
\end{tabular}

FIG 3-Management of septicaemic shock in patient with gas gangrene. Fluid and inotrope administration were varied in response to changes in heart rate, mean arterial pressure, and pulmonary artery wedge pressure. Targets for cardiovascular parameters as recommended for optimal oxygen delivery to tissue are shown. Dobutamine was given to increase cardiac output and noradrenaline and dopamine doses altered to counteract vasodilatory effect. Colloid was then needed to restore wedge pressure tissue damaged by previous injections in this area may have predisposed him to infection.

SRB: Was tumour necrosis factor measured and what part does it play?

JC: Tumour necrosis factor was first identified as a mediator of Gram negative (endotoxic) shock. There is now good evidence to suggest that the factor is also present in the circulation during staphylococcal and streptococcal sepsis. I am unaware of measurements of tumour necrosis factor in gas gangrene and it was not measured in our patient. It is not clear to what extent the factor contributes to the clinical features of shock, although in animals tumour necrosis factor antibody is highly effective in reducing these.

HJFH: You emphasised the role of preformed toxins, what is the role of clostridial antitoxin in this condition?

JC: Clostridial antitoxin was developed in the preantibiotic era, and in patients with war wounds it apparently lowered the mortality when used within the first six hours. It has never been tested in clinical trials and is no longer available.

Member of the audience: I am concerned that you have not used $\alpha$ adrenoceptor agonists. Any $\beta$ adrenoceptor agonist may help the myocardial depression but does not correct the main problem, which is the vascular collapse. With the very low systemic vascular resistance I would have thought the drug of choice would have been an $\alpha$ agonist such as methoxamine.

CTD: I support that view. You started treatment with dobutamine and minimal volume expansion, and more volume expansion was needed when the blood pressure did not respond to dobutamine. Would it not have been better to have given increased volumes initially? The main effect of dobutamine is as a $\beta$ agonist, although it also affects other receptors, and as such it may not cause a rise in blood pressure but a fall, as seen in this case.

HP: When dobutamine was started his pulmonary artery wedge pressure was elevated at $20 \mathrm{~mm} \mathrm{Hg}$. We therefore judged he was adequately filled and needed inotropic support.
AJR: In the real world all things occur together. There is evidence for both myocardial depression favouring inotropic support and low systemic vascular resistance favouring an $\alpha$ agonist. One of the factors that has improved the management of these patients is the ability to make these measurements independently and titrate treatment appropriately, as was done with this patient.

JL: On the second day there was clearly a mixed picture of hypovolaemic and septicaemic shock, in that the patient lost a large quantity of blood and was unable to increase his systemic vascular resistance appropriately, requiring an interplay between dobutamine and noradrenaline.

CDP: Does imipenem have any specific anticlostridial effect, and would you still stand by your choice of initial antibiotic? Secondly, in my experience of patients with such extensive gas gangrene (from the military viewpoint), the surgical treatment needed to be more radical, such as amputation rather than muscle debridement.

JC: Imipenem was chosen as we needed empirical treatment in an intravenous drug misuser with septicaemia and no clear focus of infection. Broad spectrum antibiotic cover was required for staphylococci, Gram negative organisms, and anaerobes, and we were reluctant to use an aminoglycoside as our patient had severely impaired renal function. Imipenem does have anticlostridial activity, indeed many antibiotics are active against clostridia, and there is no evidence that benzylpenicillin is necessarily the best antibiotic. I shall ask the surgeons to answer your second question.

ERTCO: In civilian gas gangrene amputation is not usually necessary as first line treatment, and it is more common to amputate after battlefield gas gangrene. Spontaneous gas gangrene usually affects the proximal limbs and might therefore require a hindquarter or forequarter amputation, which is associated with a high mortality. The important principle is to radically debride the necrotic muscle back to healthy tissue. This was achieved in this patient as evidenced by the profuse bleeding. Amputation may be required later if extensive tissue loss leads to poor limb function.

1 Shoemaker WC, Appel PL, Kram HB. Measurement of tissue perfusion by oxygen transport patterns in experimental shock and in high-risk surgical oxygen transport patterns in experimental shock
patients Intensive Care Med 1990;16:S135-44.

2 Bartlett JG. Gas gangrene (other clostridium-associated diseases). In: Mandell GL, Douglas GR, Bennett JE, eds. Principles and practices of infectious GL, Douglas GR, Bennett JE, eds. Principles and practices of infect
diseases. 3rd ed. Edinburgh: Churchill Livingstone, 1990:1850-60.

3 Jackson DS, Batty CG, Ryan JM, McGregor WSP. The Falklands war: army field surgical experience. Ann R Coll Surg Engl 1983;65:281-5.

4 Gibson A, Davis FM. Hyperbaric oxygen therapy in the management of Clostridium perfringens infections. N Z Med F 1986;99:617-20.

5 Tuazon CV, Hill R, Sheayren JN. Microbiologic study of street heroin and injection paraphernalia. $\mathcal{I}$ Infect Dis 1974;129:327-9

6 Kershaw CJ, Bulstrode CJK. Gas gangrene in a diabetic after intramuscular injection. Postgrad Med $\mathcal{F}$ 1988;64:812-3.

7 Sudarsky LA, Laschinger JC, Coppa GF, Spencer FC. Improved results from a standardized approach in treating patients with necrotizing fasciitis. Ann Surg 1987;206:661-5.

8 Natanson C, Danner RL, Elin RJ, Hosseini JM, Peart KW, Banks SM, et al. Role of endotoxinemia in cardiovascular dysfunction and mortality. fClin Invest 1989;83:243-51.

9 Hatheway CL. Toxigenic clostridia. Clin Microbiol Rev 1990;3:66-98.

10 Cone LA, Woodard DR, Schlievert PM, Tomory GS. Clinical and bacteriologic observations of a toxic shock-like syndrome due to Streptococcus pyogenes. N Engl f Med 1987;317:146-50.

11 Stevens DL, Troyer BE, Merrick DT, Mitten JE, Olson RD. Lethal effects and cardiovascular effects of purified $\alpha$ and $\theta$ toxins from Clostridium perfringens. F Infect Dis 1988;157:272-9.

12 Natanson C, Eichenholz PW, Danner RL, Eichacker PQ, Hoffman WD; Kuo GC, et al. Endotoxin and tumour necrosis factor challenges in dogs simulate the cardiovascular profile of human septic shock. $\mathcal{F}$ Exp Med 1989;169: the cardion.

13 Ispahani P, Pearson NJ, Greenwood D. An analysis of community and hospital-acquired bacteraemia in a large teaching hospital in the United Kingdom. Qf Med 1987;63:427-40.

14 Shoemaker WC, Appel PL, Kram HB, Waxman K, Lee TS. Prospective tria of supranormal values of survivors as therapeutic goals in high-risk surgical patients. Chest 1988;94:1176-86.

15 Edwards JD, Brown GCS, Nightingale D, et al. Use of survivors' cardiorespiratory values as therapeutic goals in septic shock. Crit Care Med (in press).

16 Gulick T, Chung MK, Pieper SJ, Lange LL, Schreiner GF. Interleukin 1 and tumour necrosis factor inhibit cardiac myocyte beta-adrenergic responsive ness. Proc Natl Acad Sci U S A 1989;86:6753-7. 